\title{
BETONARME BİR BİNANIN EŞDEĞER DEPREM YÜKÜ YÖNTEMİ İLE DBYBHY 2007 VE TBDY 2018 YÖNETMELIKLERINE GÖRE ANALİİ
}

\author{
${ }^{1}$ Mahmud Sami DÖNDÜREN ${ }^{(D)}$, ${ }^{2 S}$ Seyda HAVA ${ }^{(D)},{ }^{3}$ Ali Serdar ECEMIŞ \\ 1,2Konya Teknik Üniversitesi, Mühendislik ve Doğa Bilimleri Fakültesi, İnşaat Mühendisliği Bölümü, \\ Konya, Türkiye \\ ${ }^{3}$ Necmettin Erbakan Üniversitesi, Mühendislik Fakültesi, İnşaat Mühendisliği Bölümüu, \\ Konya, Türkiye \\ 1'msdonduren@ktun.edu.tr, 2seydahava@hotmail.com, 3asecemis@erbakan.edu.tr
}

(Geliş/Received: 24.01.2021; Kabul/Accepted in Revised Form: 05.03.2021)

\begin{abstract}
ÖZ: Aktif bir deprem kuşağında bulunan ülkemizde meydana gelen depremler sonucunda çok fazla can ve mal kayıpları yaşanmaktadır. Bu doğrultuda depreme dayanıklı yapı kalitesinin arttırılması için gerekli kurallar ve standartlar deprem yönetmelikleri şeklinde ortaya çıkmıştır. Çıkarılan deprem yönetmelikleri teknolojinin gelişmesi, deprem alanında bilgi birikiminin artması sonucu belirli zamanlarda revize edilmektedir. Son çıkarılan yönetmelik; 18 Mart 2018 yılında resmi gazetede yayınlanan ve 1 Ocak 2019 yılından itibaren kullanılmaya başlanan Türkiye Bina Deprem Yönetmeliği 2018 (TBDY 2018)' dir.

Bu çalışmada TBDY 2018 ile (Türkiye Bina Deprem Yönetmeliği) DBYBHY 2007 (Deprem Bölgelerinde Yapılacak Binalar Hakkında Yönetmelik) yönetmelikleri arasındaki farklılıklar ve benzerlikler karşılaştırılmıştır. Çalışmanın ilk bölümünde deprem ve deprem etkisi sonucu yapılarda meydana gelen hasarlar incelenmiştir. Sonraki bölümlerinde DBYBHY 2007 ile TBDY 2018 yönetmelikleri deprem hesabı açısından kıyaslanmış, seçilen modeller üzerinde sayısal olarak karşılaştırmalar yapılmıştır. Bu amaç doğrultusunda çerçeveli ve perdeli-çerçeveli taşıyıcı sisteme sahip, bodrumlu ve bodrumsuz şekilde seçilen modeller analiz edilmiştir. Modellerin İstanbul ve Konya' da olduğu, Z1-ZA ve Z3-ZD olmak üzere iki farklı yerel zemin sınıfına sahip olduğu kabulü yapılmıştır. Seçilen modeller için TBDY 2018 ile DBYBHY 2007' ye göre ayrı ayrı deprem analizleri yapılarak elde edilen sonuçlar karşılaştırılmıştır. Sonuç olarak yapılan çalışmada TBDY 2018 ile kat deplasmanlarında artış gözlenirken kat kesme kuvvetlerinde genellikle bir azalma olduğu görülmüştür.
\end{abstract}

Anahtar Kelimeler: Deprem analizi, Türkiye bina deprem yönetmeliği, eşdeğer deprem yükü

\section{An Analysis According to Regulation of DBYBHY 2007 and TBDY 2018 By Equivalent Earthquake Load Method of A Reinforced Concrete Building}

\footnotetext{
ABSTRACT: Turkey is located at high-risk seismic region. As a result of earthquakes happened in our country, loss of life and property were encountered. For this reason seismic standarts and design codes were prepared. These standards have been revised depending to technological development and increment in seismic know-how during time. The last seismic code; Turkish Building Seismic Code 2018; was published in official gazette at 18 March 2018 and come into force at 01 January 2019.

In this study; the differences and similarities between 2007 and 2018 Turkish Seismic Codes were compared. In the first part of the study seismic damages were investigated, afterwards the 2007-2018 codes were compared according to Equivalent Lateral Earthquake Load method and numerical comparisons were made on selected analysis building models. In accordance with this purpose a sample analysis building model having framed and wall-framed structural system with / without basement were selected
} 
at two locations (Konya and İstanbul) and at two soil classes ( Z1-ZA and Z3-ZD) and analysed. The analysis results were compared. As a result, TBDY 2018 concluded an increase in floor displacements and a decrease in floor shearing forces.

Key Words: Seismic analysis, Turkish Building Seismic Code, Equivalent Seismic Load

\section{GİRIŞ̧ (INTRODUCTION)}

Depremler tüm dünyada büyük can ve mal kaybının yaşandığı doğal afetlerdir. Dünyada her yıl birçok büyük deprem meydana gelmektedir. Ülkemiz coğrafi konum olarak aktif bir deprem kuşağ 1 üzerinde yer almaktadır ve ülkemizde meydana gelen depremler sonucunda çok fazla can ve mal kaybı yaşanmaktadır. Deprem sonrası meydana gelen can ve mal kayıplarından dolayı yapı projelendirme ve inşasına kurallar getirilmeye gerek duyulmuştur. Bu kurallar deprem yönetmelikleri şeklinde ortaya konulmuştur.

Gün geçtikçe özellikle deprem kuşağında bulunan ülkelerde depreme dayanıklı yapı tasarımına daha fazla önem verilmeye başlanmıştır. Türkiye topraklarının büyük bir kısmının deprem bölgesinde yer almasından dolayı yapıların depreme dayanıklı, standartlara uygun tasarlanması büyük önem arz etmektedir. Yapıların depreme dayanıklı şekilde yapılması için çıkartılan deprem yönetmelikleri zamanla gereksinimleri karşılayamadığ için revize edilmeleri gerekmektedir.

1975 yılından bu yana yapı tasarımında deprem yönetmelikleri kullanılmıştır. 2007 yılında yürürlüğe giren DBYBHY, 2007 yönetmeliğinin yerini 18 Mart 2018 tarihinde yürürlüğe giren 01.01.2019 tarihinden itibaren kullanılması zorunlu olan Türkiye Bina Deprem Yönetmeliği (TBDY, 2018) yönetmeliği almıştır. TBDY 2018 son yıllarda meydana gelen gelişmeleri, zamanla daha karmaşık bir hal alan ihtiyaçları karşılama doğrultusunda depreme dayanıklı bina tasarımını uygulamaya aktarmak adına hazırlanmıştır.

TDY 2007 yönetmeliği; mevcut binaların değerlendirilmesi ve güçlendirilmesi amacı ile yeni eklenen bir bölüm ve çelik binalar bölümünde yapılan değişiklikler bir kenara bırakıldığında 1997 yılında çıkarılmış deprem yönetmeliğinden 21 yıl sonra ilk defa yenilenmektedir. Bu geçen sürede mühendislik alanında yapılan çalışmaların artması, bina teknolojisinde meydana gelen gelişmeler, depremin yapı üzerindeki etkisinin, deprem anında taşıyıcı sistem elemanlarının gerçeğe daha yakın halde belirlenebilmesi, bu bağlamda yüksek binaların daha da yaygınlaşması böyle bir yönetmelik değişikliğinin gerekliliğini ortaya koymaktadır.

Deprem anında yapının ayakta kalmasını sağlayarak can kaybını ve olası felaketleri engellemek bu güncel yönetmelikleri iyi bir şekilde anlayıp uygulamaya geçirmekle mümkündür. Bunu yapabilmek inşaat mühendislerinin en büyük sorumluluklarından biridir.

Deprem yönetmeliklerini daha iyi anlamak ve uygulamak adına literatürde farklı çalışmalar yapılmıştır. Bu çalışmalarda; Kırklareli' nde seçilen dört katlı bir yapı farklı zemin sınıfları için TDY 2007 ve TBDY 2018' e göre deprem analizi yapılarak elde edilen sonuçlar karşılaştırılmıştır (Keskin ve diğ.,2018). Benzer şekilde TDY 2007 ve TBDY 2018 yönetmeliklerinin hesap ve tasarım esaslarındaki benzerlik ve farklılıklar incelenerek bunların tasarımda ortaya çıkardığı etkiler Sapanca' da seçilen örnek bir bina modelinde analiz edilerek TBDY 2018' de TDY 2007' ye kıyasla oluşan farklılıkların yapı elemanlarının tasarımında yapacağı etkiler araştırılmıştır (Tunç ve diğ,.2016). Bir diğer çalışmada çelik yapı tasarımındaki yenilikleri incelemek adına iki adet çelik yapı TBDY 2018 gereklilikleri dikkate alınarak tasarlanıp analiz edilmiştir. Tasarım aşamasında TDY 2007 ile karşılaştırma yapılarak sonuçlar irdelenmiştir (Zorlu ve diğ., 2017). Bu çalışmalarda olduğu gibi TDY 2007' ye göre TBDY 2018 yönetmeliğinin getirdiği yeniliklerin ve farklılıkların incelendiği, farklı taşıyıcı sistemler ve parametreler esas alınarak seçilen yapı sistemlerinin analiz edilip sonuçlarının değerlendirildiği benzer çalışmalar (Erdem ve diğ., 2017, Demir ve diğ,. 2017, Öztürk, 2018, Öztürk ve diğ,. 2017, Sürmeli, 2017) TBDY 2018 yönetmeliğinin getirmiş olduğu deprem hesabı ve tasarımsal yenilikleri anlamakta bizlere yol gösterici olmaktadır. 
Yapılan bu çalışmada; TDY 2007 yönetmeliği ile TBDY 2018 yönetmeliğinin deprem hesabı açısından farklı taşıyıcı sistemlere sahip modeller üzerinde analizler yapılıp sayısal olarak karşılaştırılmıştır.

\section{MATERYAL ve YÖNTEM (MATERIAL and METHOD)}

\section{Modellere İlişkin Genel Bilgiler (General Information on Models)}

TDY 2007 ve TBDY 2018 yönetmeliklerinin deprem hesabı açısından ortaya çıkacak sayısal farklılıkların incelenmesi için seçilen modeller her iki yönetmeliğe göre analiz edilmiştir. Taşıyıcı sistem modellerinin 3 boyutlu modellemesi ve analizleri yapısal analiz programı ETABS v16 2.0 kullanılarak yapılmıştır.

Modellerin tamamı aynı geometriye sahiptir ve modeller aşağıda verilen 4 sisteme göre analiz edilmiştir.

Grup 1: 9 normal kat ve 1 çatı katından oluşan çerçeveli sistem,

Grup 2: 1 bodrum, 8 normal kat ve 1 çatı katından oluşan çerçeveli sistem,

Grup 3: 9 normal kat ve 1 çatı katından oluşan çerçeveli- perdeli sistem,

Grup 4: 1 bodrum, 8 normal kat ve 1 çatı katından oluşan çerçeveli- perdeli sistem,

Analizleri yapılacak modellerin Konya ve İstanbul illerinde olduğu kabul edilmiştir. Modellerin plan boyutları akstan aksa $17.70 \mathrm{~m}$ x $32.00 \mathrm{~m}$, X yönü aks aralıkları $4.00 \mathrm{~m}$, Y yönü aks aralıkları sırayla $7.50 \mathrm{~m}$, $2.50 \mathrm{~m}, 7.50 \mathrm{~m}$ 'dir. Kat yüksekliği her katta $3.80 \mathrm{~m}$ toplam bina yüksekliği $38 \mathrm{~m}$ olup tüm modeller 10 katlı olarak modellenmiştir. Taşıyıcı sistem modeli belirlenirken kat planında düzenli bir taşıyıcı eleman yerleşimi yapılarak düzensizlik etkisi göz önüne alınmamıştır. Binanın kullanım amacı I=1 olan otel, konut, misafirhane türü yapı olarak seçilmiştir ve hareketli yük katılım katsayısı $n=0.3$ olarak alınmıştır.

Taşıyıcı sistem; deprem etkilerinin süneklik düzeyi yüksek betonarme çerçevelerle karşılandığı binalar ve deprem etkilerinin süneklik düzeyi yüksek betonarme perdeler ve çerçevelerle karşılandığı binalar olmak üzere iki farklı taşıyıcı sisteme göre modellenmiştir. Modellere ait yerel zemin sınıfları TDY 2007'ye göre Z1 ve Z3, TBDY 2018'e göre ZA ve ZD olarak seçilmiştir. Seçilen iki yerel zemin sınıfına, taşıyıcı sisteme bodrum ve bodrumsuz olmasına göre toplamda 32 adet model bulunmaktadır (Çizelge 1).

Analizleri yapılan modellere ait taşıyıcı sistem eleman boyutları tüm modellerde aynıdır. Taşıyıcı sistem eleman boyutları;

Kolon boyutlari: $40 / 80 \mathrm{~cm}$ ve $80 / 40 \mathrm{~cm}$

Kiriş boyutları: $30 / 60 \mathrm{~cm}$

Perde boyutları: 30/210 cm

Bodrum perdesi kalınlığı: $30 \mathrm{~cm}$ 
Çizelge 1. Bina modelleri

Table 1. Building models

\begin{tabular}{|c|c|c|c|c|c|c|}
\hline & & MODEL ADI & $\begin{array}{c}\text { TAŞIYICI SİSTEM } \\
\text { TÜß̈̈ }\end{array}$ & $\begin{array}{l}\text { BODRUMLU/ } \\
\text { BODRUMSUZ }\end{array}$ & $\begin{array}{l}\text { YEREL } \\
\text { ZEMİN }\end{array}$ & İL \\
\hline & & & & & SINIFI & \\
\hline \multirow{16}{*}{$\begin{array}{l}\text { TDY } \\
2007\end{array}$} & \multirow{4}{*}{ GRUP 1} & MODEL 1 & Çerçeve & Bodrumsuz & Z1 & İstanbul \\
\hline & & MODEL 2 & Çerçeve & Bodrumsuz & $\mathrm{Z1}$ & Konya \\
\hline & & MODEL 3 & Çerçeve & Bodrumsuz & $\mathrm{Z3}$ & İstanbul \\
\hline & & MODEL 4 & Çerçeve & Bodrumsuz & $\mathrm{Z3}$ & Konya \\
\hline & \multirow{4}{*}{ GRUP 2} & MODEL 5 & Çerçeve & Bodrumlu & $\mathrm{Z1}$ & İstanbul \\
\hline & & MODEL 6 & Çerçeve & Bodrumlu & Z1 & Konya \\
\hline & & MODEL 7 & Çerçeve & Bodrumlu & Z3 & İstanbul \\
\hline & & MODEL 8 & Çerçeve & Bodrumlu & Z3 & Konya \\
\hline & \multirow{4}{*}{ GRUP 3} & MODEL 9 & Çerçeve-Perde & Bodrumsuz & $\mathrm{Z1}$ & İstanbul \\
\hline & & MODEL 10 & Çerçeve-Perde & Bodrumsuz & $\mathrm{Z1}$ & Konya \\
\hline & & MODEL 11 & Çerçeve-Perde & Bodrumsuz & Z3 & İstanbul \\
\hline & & MODEL 12 & Çerçeve-Perde & Bodrumsuz & $\mathrm{Z3}$ & Konya \\
\hline & \multirow{4}{*}{ GRUP 4} & MODEL 13 & Çerçeve-Perde & Bodrumlu & $\mathrm{Z1}$ & İstanbul \\
\hline & & MODEL 14 & Çerçeve-Perde & Bodrumlu & $\mathrm{Z1}$ & Konya \\
\hline & & MODEL 15 & Çerçeve-Perde & Bodrumlu & $\mathrm{Z3}$ & İstanbul \\
\hline & & MODEL 16 & Çerçeve-Perde & Bodrumlu & $\mathrm{Z3}$ & Konya \\
\hline \multirow{16}{*}{$\begin{array}{l}\text { TBDY } \\
2018\end{array}$} & \multirow{4}{*}{ GRUP 1} & MODEL 1 & Çerçeve & Bodrumsuz & $\mathrm{ZA}$ & İstanbul \\
\hline & & MODEL 2 & Çerçeve & Bodrumsuz & $\mathrm{ZA}$ & Konya \\
\hline & & MODEL 3 & Çerçeve & Bodrumsuz & ZD & İstanbul \\
\hline & & MODEL 4 & Çerçeve & Bodrumsuz & $\mathrm{ZD}$ & Konya \\
\hline & \multirow{4}{*}{ GRUP 2} & MODEL 5 & Çerçeve & Bodrumlu & $\mathrm{ZA}$ & İstanbul \\
\hline & & MODEL 6 & Çerçeve & Bodrumlu & $\mathrm{ZA}$ & Konya \\
\hline & & MODEL 7 & Çerçeve & Bodrumlu & $\mathrm{ZD}$ & İstanbul \\
\hline & & MODEL 8 & Çerçeve & Bodrumlu & ZD & Konya \\
\hline & \multirow{4}{*}{ GRUP 3} & MODEL 9 & Çerçeve-Perde & Bodrumsuz & $\mathrm{ZA}$ & İstanbul \\
\hline & & MODEL 10 & Çerçeve-Perde & Bodrumsuz & $\mathrm{ZA}$ & Konya \\
\hline & & MODEL 11 & Çerçeve-Perde & Bodrumsuz & $\mathrm{ZD}$ & İstanbul \\
\hline & & MODEL 12 & Çerçeve-Perde & Bodrumsuz & $\mathrm{ZD}$ & Konya \\
\hline & \multirow{4}{*}{ GRUP 4} & MODEL 13 & Çerçeve-Perde & Bodrumlu & $\mathrm{ZA}$ & İstanbul \\
\hline & & MODEL 14 & Çerçeve-Perde & Bodrumlu & $\mathrm{ZA}$ & Konya \\
\hline & & MODEL 15 & Çerçeve-Perde & Bodrumlu & $\mathrm{ZD}$ & İstanbul \\
\hline & & MODEL 16 & Çerçeve-Perde & Bodrumlu & $\mathrm{ZD}$ & Konya \\
\hline
\end{tabular}

Döşeme kalınlığg: $15 \mathrm{~cm}$ seçilmiştir.

Modellerde esas alınan ölü ve hareketli yükler TS- 498'e göre belirlenmiştir.

Ölü Yük:

Betonarme elemanın zati ağırlığı: $\gamma=24,5 \mathrm{kN} / \mathrm{m}^{3}$

Kaplama Yükü

: $\mathrm{g}=3.00 \mathrm{kN} / \mathrm{m}^{2}$

Dış Cephe Duvarı

: $\mathrm{g}=0.230 \mathrm{kN} / \mathrm{m}^{2}$

İç Bölme Duvar

: $\mathrm{g}=0.146 \mathrm{kN} / \mathrm{m}^{2}$

Hareketli Yük:

Koridor, Balkon

: $\mathrm{q}=5.00 \mathrm{kN} / \mathrm{m}^{2}$

Oda

: $\mathrm{q}=3.50 \mathrm{kN} / \mathrm{m}^{2}$ 
Çatı katı : $\mathrm{q}=2.00 \mathrm{kN} / \mathrm{m}^{2}$

Yerçekimi ivmesi g=9.81 m/s² alınmıştır.

Seçilen modellere ait kalıp planları Şekil 1 ve Şekil 2' de verilmiştir.

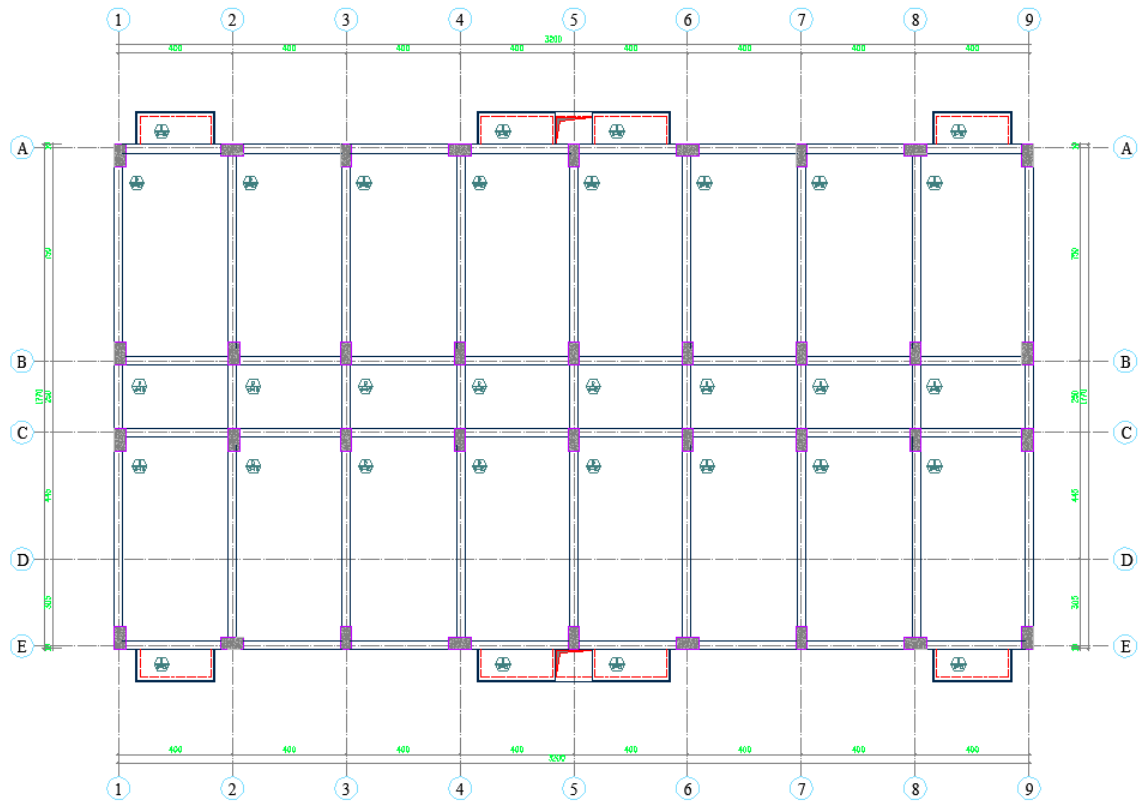

Şekil 1. Çerçeve taşıyıcı sistemli modele ait kalıp

Figure 1. Formwork plan of the model with framed carrier system

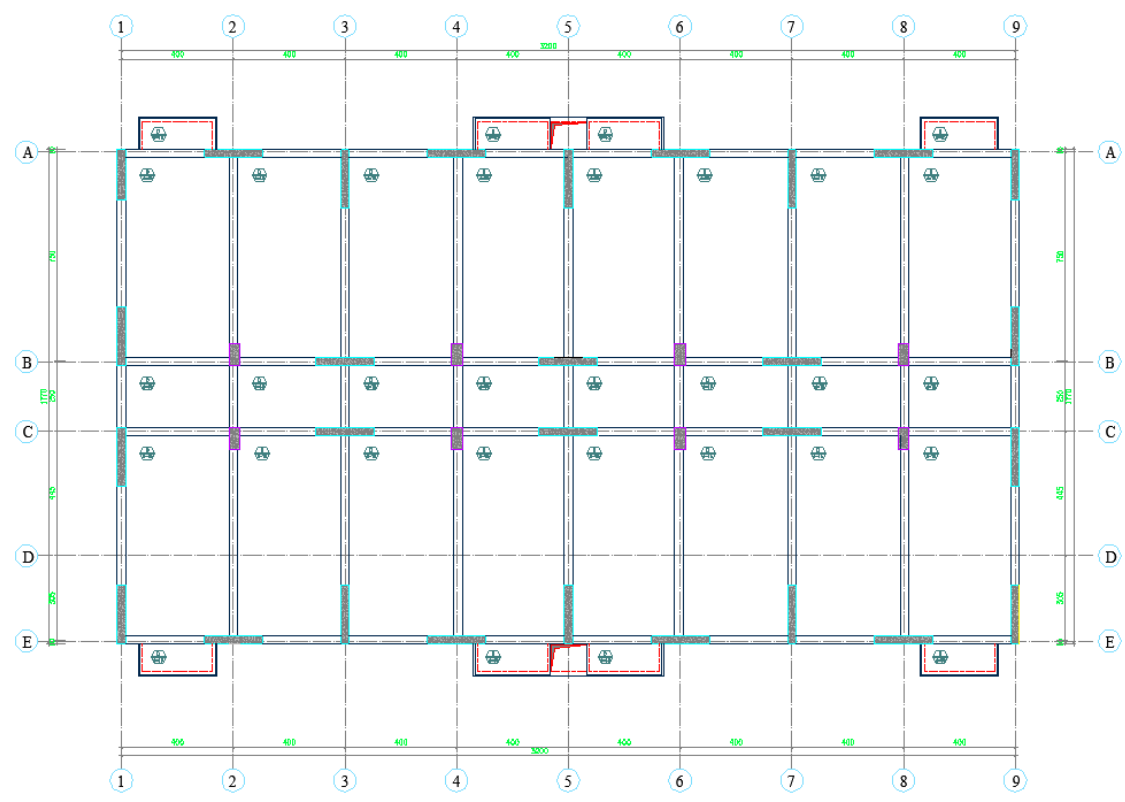

Şekil 2. Çerçeveli-perdeli taşıyıcı sistemli modele ait kalıp planı Figure 2. Formwork plan for the wall - framed carrier system model

ETABS programında oluşturulan modellerde kolon ve kirişler çubuk sonlu eleman (frame), perdeler ve TBDY 2018'de tanımlanan normal katlardan çok rijit bodrum katlarına geçişte yer alan geçiş kat döşemesi kabuk sonlu eleman (shell) olarak modellenmiştir. Perdeler ve geçiş kat döşemesi uygun boyutlardaki sonlu elemanlara (mesh) ayrılmıştır. Normal kat döşemeleri membran olarak 
tanımlanmıştır. TBDY 2018' e göre yapılan analizlerde taşıyıcı sistem elemanlarına yönetmelikte yer alan etkin kesit rijitlik katsayısı verilmiştir.

\section{Deprem Parametreleri ( Earthquake Parameters)}

Modellerin deprem analizleri Eşdeğer Deprem Yükü Yöntemine göre yapılmıştır. TDY 2007'ye göre İstanbul 1.Derece, Konya 4. Derece deprem bölgesindedir ve tasarım ivme spektrumu deprem bölgesi ve zemin sınıfı göz önüne alınarak yönetmelikten elde edilmiştir. TBDY 2018'de ise İstanbul (Enlem 41.018071, Boylam 29.15173) ve Konya (Enlem 37.869972, Boylam 32.494208) için tasarım ivme spektrumunun elde edilmesi için gerekli olan harita spektral ivme katsayıları https://tdth.afad.gov.tr adresindeki Deprem Tehlike Haritaları'ndan elde edilmiştir. Analizler için seçilen modellere etki edecek deprem kuvvetlerinin hesabında kullanılan parametreler Çizelge 2 ve Çizelge 3'de verilmiştir.

Çizelge 2. TBDY 2018 deprem hesap parametreleri

Table 2. TBDY 2018 earthquake account parameters

\begin{tabular}{|c|c|c|c|c|c|c|c|c|c|c|c|c|c|c|c|c|}
\hline \multirow{3}{*}{$\begin{array}{l}\text { Taşıyıcı } \\
\text { Sistem } \\
\begin{array}{c}\text { Model } \\
\text { Adı }\end{array} \\
\end{array}$} & \multicolumn{16}{|c|}{ TBDY 2018} \\
\hline & \multicolumn{4}{|c|}{ Çerçeveli-Bodrumsuz } & \multicolumn{5}{|c|}{ Çerçeveli-Bodrumlu } & \multicolumn{4}{|c|}{ Çerçeveli-Perdeli Bodrumsuz } & \multicolumn{3}{|c|}{$\begin{array}{l}\text { Çerçeveli-Perdeli } \\
\text { Bodrumlu }\end{array}$} \\
\hline & $\begin{array}{c}\text { Model } \\
1 \\
\end{array}$ & $\begin{array}{c}\text { Model } \\
2 \\
\end{array}$ & $\begin{array}{c}\text { Model } \\
3 \\
\end{array}$ & $\begin{array}{c}\text { Model } \\
4 \\
\end{array}$ & $\begin{array}{c}\text { Model } \\
5 \\
\end{array}$ & $\begin{array}{c}\text { Model } \\
6 \\
\end{array}$ & $\begin{array}{c}\text { Model } \\
7 \\
\end{array}$ & $\begin{array}{c}\text { Model } \\
8 \\
\end{array}$ & $\begin{array}{c}\text { Model } \\
9 \\
\end{array}$ & $\begin{array}{c}\text { Model } \\
10 \\
\end{array}$ & $\begin{array}{c}\text { Model } \\
11 \\
\end{array}$ & $\begin{array}{c}\text { Model } \\
12 \\
\end{array}$ & $\begin{array}{c}\text { Model } \\
13 \\
\end{array}$ & $\begin{array}{c}\text { Model } \\
14 \\
\end{array}$ & $\begin{array}{c}\text { Model } \\
15 \\
\end{array}$ & $\begin{array}{c}\text { Model } \\
16\end{array}$ \\
\hline $\mathbf{T}_{x}$ & 2.17 & 2.17 & 2.17 & 2.17 & 1.98 & 1.98 & 1.98 & 1.98 & 1.84 & 1.84 & 1.84 & 1.84 & 1.67 & 1.67 & 1.67 & 1.67 \\
\hline $\mathbf{T}_{\mathrm{y}}$ & 2.34 & 2.34 & 2.34 & 2.34 & 2.16 & 2.16 & 2.16 & 2.16 & 1.93 & 1.93 & 1.93 & 1.93 & 1.75 & 1.75 & 1.75 & 1.75 \\
\hline $\mathrm{S}_{\mathrm{s}}$ & 0.802 & 0.306 & 0.802 & 0.306 & 0.802 & 0.306 & 0.802 & 0.306 & 0.802 & 0.306 & 0.802 & 0.306 & 0.802 & 0.306 & 0.802 & 0.306 \\
\hline $\mathrm{S}_{1}$ & 0.226 & 0.073 & 0.226 & 0.073 & 0.226 & 0.073 & 0.226 & 0.073 & 0.226 & 0.073 & 0.226 & 0.073 & 0.226 & 0.073 & 0.226 & 0.073 \\
\hline Sos & 0.642 & 0.245 & 0.946 & 0.476 & 0.642 & 0.245 & 0.946 & 0.476 & 0.642 & 0.245 & 0.946 & 0.476 & 0.642 & 0.245 & 0.946 & 0.476 \\
\hline $\mathrm{S}_{\mathrm{D} 1}$ & 0.181 & 0.058 & 0.485 & 0.175 & 0.181 & 0.058 & 0.485 & 0.175 & 0.181 & 0.058 & 0.485 & 0.175 & 0.181 & 0.058 & 0.485 & 0.175 \\
\hline $\mathrm{T}_{\mathrm{A}} / \mathrm{T}_{\mathrm{B}}$ & $\begin{array}{c}0.056 / \\
0.282\end{array}$ & $\begin{array}{c}0.048 / \\
0.239\end{array}$ & $\begin{array}{c}0.103 / \\
0.513\end{array}$ & $\begin{array}{c}0.074 / \\
0.368\end{array}$ & $\begin{array}{c}0.056 / \\
0.282\end{array}$ & $\begin{array}{l}0.048 / \\
0.239\end{array}$ & $\begin{array}{c}0.103 / \\
0.513\end{array}$ & $\begin{array}{c}0.074 / \\
0.368\end{array}$ & $\begin{array}{c}0.056 / \\
0.282\end{array}$ & $\begin{array}{c}0.048 \\
/ 0.239\end{array}$ & $\begin{array}{c}0.103 / \\
0.513\end{array}$ & $\begin{array}{c}0.074 / \\
0.368\end{array}$ & $\begin{array}{c}0.056 / \\
0.282\end{array}$ & $\begin{array}{c}0.048 / \\
0.239\end{array}$ & $\begin{array}{c}0.103 / \\
0.513\end{array}$ & $\begin{array}{c}0.074 / \\
0.368\end{array}$ \\
\hline$T_{\mathrm{L}}$ & 6 & 6 & 6 & 6 & 6 & 6 & 6 & 6 & 6 & 6 & 6 & 6 & 6 & 6 & 6 & 6 \\
\hline D & 3 & 3 & 3 & 3 & 3 & 3 & 3 & 3 & 2.5 & 2.5 & 2.5 & 2.5 & 2.5 & 2.5 & 2.5 & 2.5 \\
\hline BKS & 3 & 3 & 3 & 3 & 3 & 3 & 3 & 3 & 3 & 3 & 3 & 3 & 3 & 3 & 3 & 3 \\
\hline DTS & 2 & 4 & 1 & 3 & 2 & 4 & 1 & 3 & 2 & 4 & 1 & 3 & 2 & 4 & 1 & 3 \\
\hline BYS & 4 & 5 & 4 & 5 & 4 & 5 & 4 & 5 & 4 & 5 & 4 & 5 & 4 & 5 & 4 & 5 \\
\hline
\end{tabular}


Çizelge 3. TDY 2007 deprem hesap parametreleri Table 3. TDY 2007 earthquake account parameters

\begin{tabular}{|c|c|c|c|c|c|c|c|c|c|c|c|c|c|c|c|c|}
\hline \multirow{3}{*}{$\begin{array}{c}\begin{array}{c}\text { Tassyyıcı } \\
\text { Sistem }\end{array} \\
\begin{array}{c}\text { Model } \\
\text { Ad1 }\end{array}\end{array}$} & \multicolumn{16}{|c|}{ TDY 2007} \\
\hline & \multicolumn{4}{|c|}{ Çerçeveli-Bodrumsuz } & \multicolumn{4}{|c|}{ Çerçeveli-Bodrumlu } & \multicolumn{4}{|c|}{ Çerçeveli-Perdeli Bodrumsuz } & \multicolumn{4}{|c|}{ Çerçeveli-Perdeli Bodrumlu } \\
\hline & $\begin{array}{c}\text { Model } \\
1\end{array}$ & $\begin{array}{c}\text { Model } \\
2\end{array}$ & $\begin{array}{c}\text { Model } \\
3\end{array}$ & $\begin{array}{c}\text { Model } \\
4\end{array}$ & $\begin{array}{c}\text { Model } \\
5\end{array}$ & $\begin{array}{c}\text { Model } \\
6\end{array}$ & $\begin{array}{c}\text { Model } \\
7\end{array}$ & $\begin{array}{c}\text { Model } \\
8\end{array}$ & $\begin{array}{c}\text { Model } \\
9\end{array}$ & $\begin{array}{c}\text { Model } \\
10\end{array}$ & $\begin{array}{c}\text { Model } \\
11\end{array}$ & $\begin{array}{c}\text { Model } \\
12\end{array}$ & $\begin{array}{c}\text { Model } \\
13\end{array}$ & $\begin{array}{l}\text { Model } \\
14\end{array}$ & $\begin{array}{c}\text { Model } \\
15\end{array}$ & $\begin{array}{c}\text { Model } \\
16\end{array}$ \\
\hline$T_{x}$ & 1.52 & 1.52 & 1.52 & 1.52 & 1.38 & 1.38 & 1.38 & 1.38 & 1.23 & 1.23 & 1.23 & 1.23 & 1.12 & 1.12 & 1.12 & 1.12 \\
\hline$T_{y}$ & 1.60 & 1.60 & 1.60 & 1.60 & 1.47 & 1.47 & 1.47 & 1.47 & 1.27 & 1.27 & 1.27 & 1.27 & 1.16 & 1.16 & 1.16 & 1.16 \\
\hline $\begin{array}{l}\text { Deprem } \\
\text { Bölgesi }\end{array}$ & 1 & 4 & 1 & 4 & 1 & 4 & 1 & 4 & 1 & 4 & 1 & 4 & 1 & 4 & 1 & 4 \\
\hline $\begin{array}{c}\text { Etkin } \\
\text { Yer } \\
\text { İvmesi } \\
\text { Katsayisi } \\
\left(\mathrm{A}_{0}\right)\end{array}$ & 0.4 & 0.1 & 0.4 & 0.1 & 0.4 & 0.1 & 0.4 & 0.1 & 0.4 & 0.1 & 0.4 & 0.1 & 0.4 & 0.1 & 0.4 & 0.1 \\
\hline $\mathrm{T}_{\mathrm{A}} / \mathrm{T}_{\mathrm{B}}$ & $\begin{array}{l}0.10 / \\
0.30\end{array}$ & $\begin{array}{c}0.10 / \\
0.30\end{array}$ & $\begin{array}{c}0.15 / \\
0.60\end{array}$ & $\begin{array}{l}0.15 / \\
0.60\end{array}$ & $\begin{array}{l}0.10 / \\
0.30\end{array}$ & $\begin{array}{c}0.10 / \\
0.30\end{array}$ & $\begin{array}{c}0.15 / \\
0.60\end{array}$ & $\begin{array}{c}0.15 / \\
0.60\end{array}$ & $\begin{array}{c}0.10 / \\
0.30\end{array}$ & $\begin{array}{c}0.10 / \\
0.30\end{array}$ & $\begin{array}{c}0.15 / \\
0.60\end{array}$ & $\begin{array}{c}0.15 / \\
0.60\end{array}$ & $\begin{array}{c}0.10 / \\
0.30\end{array}$ & $\begin{array}{l}0.10 / \\
0.30\end{array}$ & $\begin{array}{c}0.15 / \\
0.60\end{array}$ & $\begin{array}{c}0.15 / \\
0.60\end{array}$ \\
\hline
\end{tabular}

Döşemelerin kendi düzleminde rijit diyafram olduğu ve kat kütlelerinin kat kütle merkezinde toplandığı kabul edilmiştir. Kat kesme kuvvetleri \%5 eksantrisite dikkate alınarak kat kütle merkezlerine etki ettirilmiştir. Deprem kuvvetleri binaya her iki doğrultuda ayrı ayrı etki ettirilmiştir.

TBDY 2018' e göre yapılan deprem hesabında kullanılan hakim doğal titreşim periyotları Çizelge 4' de verilmiştir.

Çizelge 4. TBDY 2018' e göre hesapta kullanılan periyotlar Table 4. Periods used in the account according to TBDY 2018

\begin{tabular}{|c|c|c|c|c|c|c|}
\hline \multicolumn{7}{|c|}{ TBDY 2018} \\
\hline \multirow{2}{*}{ Taşıyıcı Sistem } & \multicolumn{2}{|c|}{ ETABS } & \multicolumn{2}{|c|}{$1.4 \mathrm{~T}_{\mathrm{pA}}$} & \multicolumn{2}{|c|}{$\begin{array}{c}\text { Hesapta } \\
\text { Kullanılan Periyot }\end{array}$} \\
\hline & $\mathbf{T}_{\mathbf{x}}$ & $\mathbf{T}_{\mathbf{y}}$ & $\mathbf{T}_{\mathbf{x}}$ & $\mathbf{T}_{\mathbf{y}}$ & $\mathbf{T}_{\mathbf{x}}$ & $\mathbf{T}_{\mathbf{y}}$ \\
\hline Çerçeveli-Bodrumsuz & 2.17 & 2.34 & 2.14 & 2.14 & 2.14 & 2.14 \\
\hline Çerçeveli-Bodrumlu & 1.98 & 2.16 & 1.98 & 1.98 & 1.98 & 1.98 \\
\hline $\begin{array}{c}\text { Çerçeveli-Perdeli } \\
\text { Bodrumsuz }\end{array}$ & 1.84 & 1.93 & 1.50 & 1.50 & 1.50 & 1.50 \\
\hline Çerçeveli-Perdeli Bodrumlu & 1.67 & 1.75 & 1.38 & 1.38 & 1.38 & 1.38 \\
\hline
\end{tabular}

TDY 2007' ye göre yapılan deprem hesabında kullanılan hakim doğal titreşim periyotları Çizelge 5' de verilmiştir. 
Çizelge 5. TDY 2007' ye göre hesapta kullanılan periyotlar Table 5. Periods used in the account according to TDY 2007

\begin{tabular}{|c|c|c||}
\hline \multicolumn{3}{|c|}{ TDY 2007} \\
\hline \multirow{2}{*}{ Taşıyıcı Sistem } & \multicolumn{2}{|c||}{ Hesapta Kullanılan Periyot } \\
\cline { 2 - 3 } & $\mathbf{T}_{\mathbf{x}}$ & $\mathbf{T}_{\mathbf{y}}$ \\
\hline Çerçeve-Bodrumsuz & 1.52 & 1.60 \\
\hline Çerçeve-Bodrumlu & 1.38 & 1.47 \\
\hline $\begin{array}{c}\text { Çerçeveli-Perdeli } \\
\text { Bodrumsuz }\end{array}$ & 1.23 & 1.27 \\
\hline Çerçeveli-Perdeli Bodrumlu & 1.12 & 1.16 \\
\hline
\end{tabular}

Modellerin deprem hesabında kullanılan R katsayıları Çizelge 6' da verilmiştir.

Çizelge 6. Hesapta kullanılan R katsayıları

Table 6. $R$ coefficients used in the account

\begin{tabular}{|c|c|c|c|c||}
\hline \multirow{2}{*}{ Taşıyıcı Sistem } & \multicolumn{4}{|c|}{ R Katsayısı } \\
\cline { 2 - 5 } & \multicolumn{2}{|c|}{ TDY 2007} & \multicolumn{2}{|c|}{ TBDY 2018} \\
\cline { 2 - 5 } & $\mathbf{R}_{\mathbf{x}}$ & $\mathbf{R}_{\mathbf{y}}$ & $\mathbf{R}_{\mathbf{x}}$ & $\mathbf{R}_{\mathbf{y}}$ \\
\hline Çerçeve-Bodrumsuz & 8.00 & 8.00 & 8.00 & 8.00 \\
\hline Çerçeve-Bodrumlu & 8.00 & 8.00 & 8.00 & 8.00 \\
\hline Çerçeveli-Perdeli Bodrumsuz & 6.48 & 6.68 & 7.00 & 7.00 \\
\hline Çerçeveli-Perdeli Bodrumlu & 6.60 & 6.68 & 7.00 & 7.00 \\
\hline
\end{tabular}

\section{Analiz Sonuçlarının Karşılaştırılması (Comparison of Analysis Results)}

Tüm modeller için TDY 2007 ve TBDY 2018' e göre yapılan analizler sonucunda X ve Y deprem doğrultusunda meydana gelen kat deplasmanları ve kat kesme kuvvetleri Şekil 3-Şekil 10' da verilmiştir. Verilen bu grafiklerden kat deplasmanı miktarında ve kat kesme kuvvetinde meydana gelen fark TDY 2007 ve TBDY 2018 için de karşılaştırmalı olarak görülmektedir.

Çerçeveli - bodrumsuz modellerin karşılaştırılması (Comparison of framed-without basement models)

Çerçeveli bodrumsuz model 1-3 için kat deplasmanları ve kat kesme kuvvetleri dağılımı Şekil 3'de, çerçeveli bodrumsuz model 2-4 için kat deplasmanları ve kat kesme kuvvetleri dağılımı Şekil 4'de verilmiştir. 


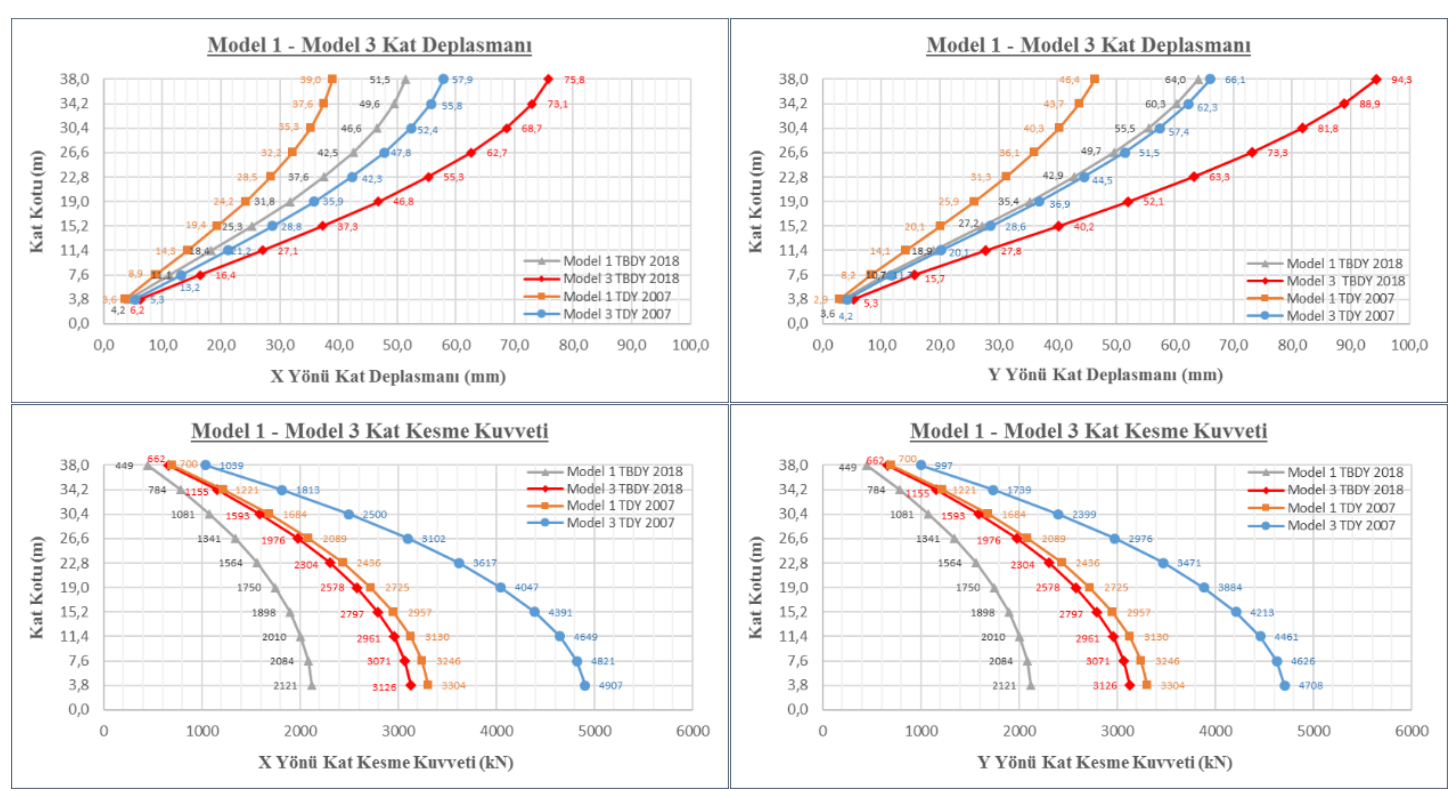

Şekil 3. Model 1-Model $3 \mathrm{X}$ ve Y yönü kat deplasmanları ve kat kesme kuvvetlerinin TDY 2007 ve TBDY 2018' e göre karşılaştırması

Figure 3.Model 1-Model $3 \mathrm{X}$ and Y direction floor displacements and floor shearing forces according to TDY 2007 and TBDY 2018

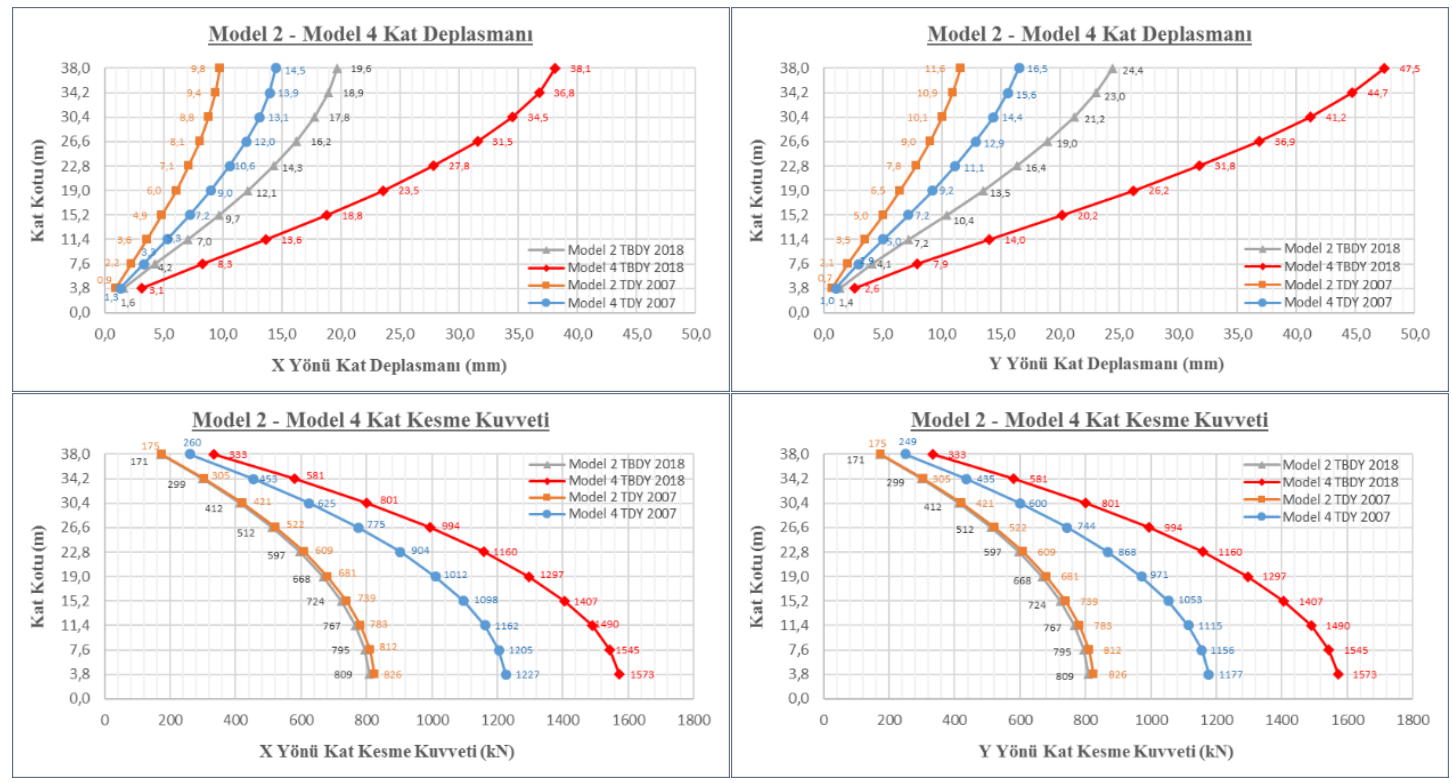

Şekil 4. Model 2-Model $4 \mathrm{X}$ ve Y yönü kat deplasmanları ve kat kesme kuvvetlerinin TDY 2007 ve TBDY 2018' e göre karşılaştırması

Figure 4. Model 2-Model 4 X and Y direction floor displacements and floor shearing forces according to TDY 2007 and TBDY 2018

\section{Çerçeveli - bodrumlu modellerin karşılaştırılması (Comparison of framed- with basement models)}

Çerçeveli bodrumlu model 5-7 için kat deplasmanları ve kat kesme kuvvetleri dağılımı Şekil 5'de, çerçeveli bodrumlu model 6-8 için kat deplasmanları ve kat kesme kuvvetleri dağılımı Şekil 6’da verilmiştir. 

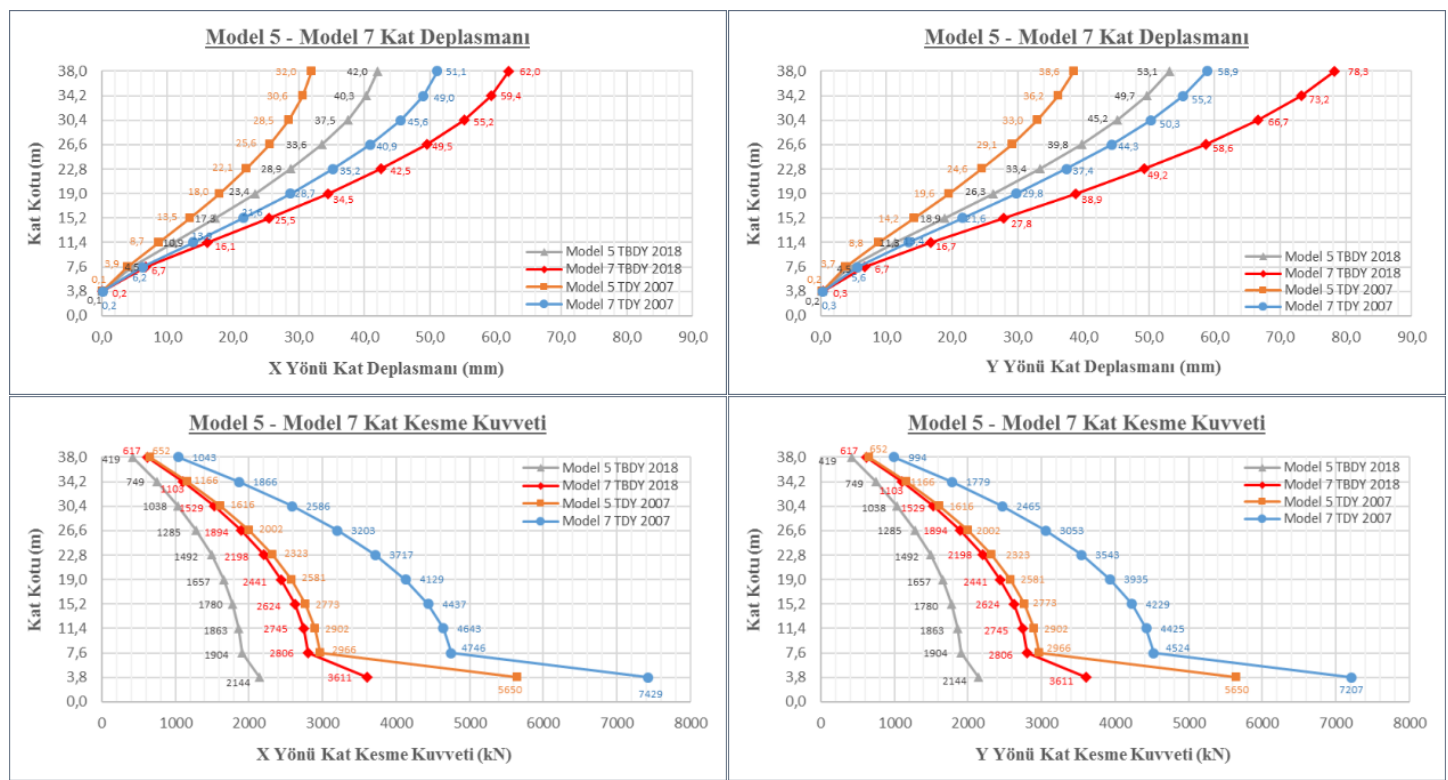

Şekil 5. Model 5-Model 7 X ve Y yönü kat deplasmanları ve kat kesme kuvvetlerinin TDY 2007 ve TBDY 2018' e göre karşılaştırması

Figure 5.Model 5-Model $7 \mathrm{X}$ and $Y$ direction floor displacements and floor shearing forces according to TDY 2007 and TBDY 2018

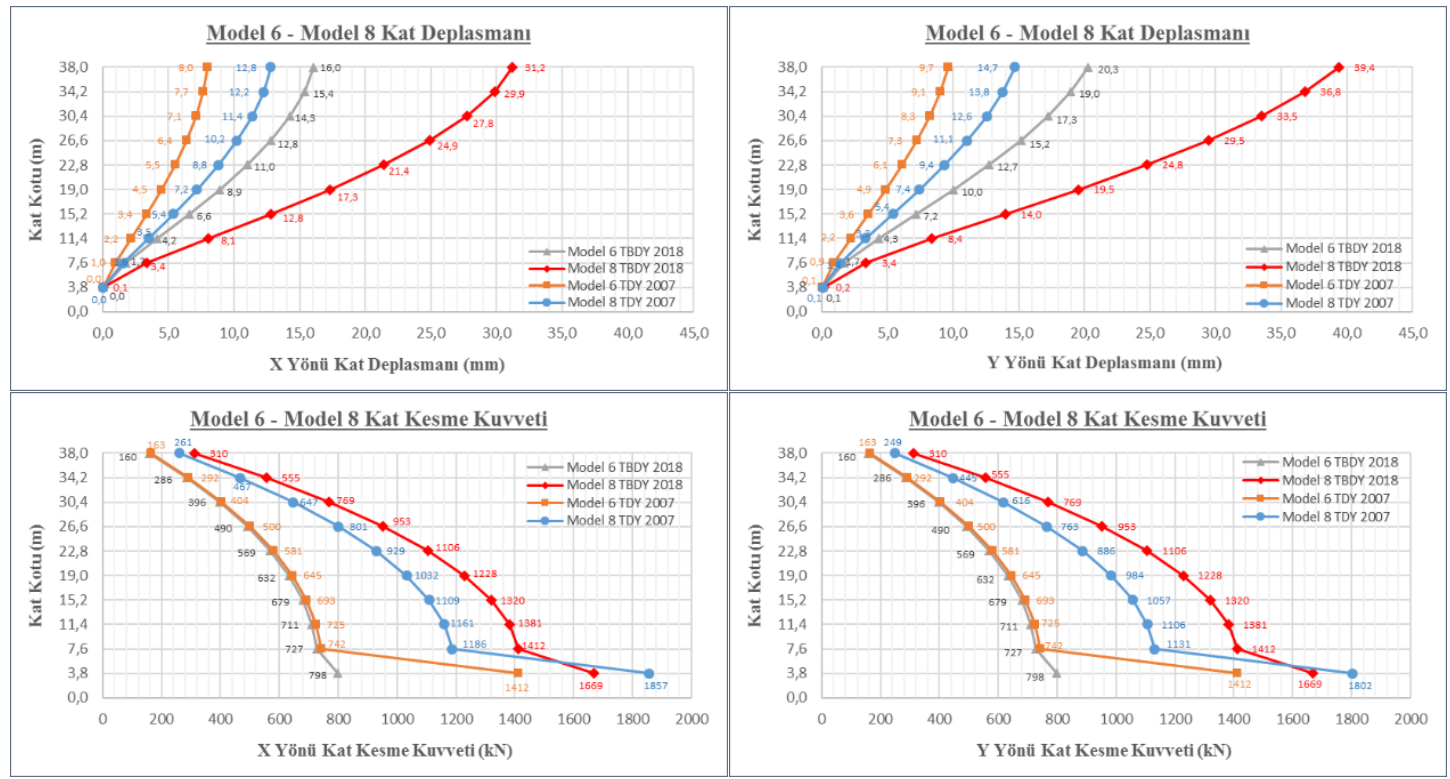

Şekil 6. Model 6-Model 8 X ve Y yönü kat deplasmanları ve kat kesme kuvvetlerinin TDY 2007 ve TBDY 2018' e göre karşılaştırması

Figure 6. Model 6-Model 8 X and Y direction floor displacements and floor shearing forces according to TDY 2007 and TBDY 2018

\section{Çerçeveli - perdeli bodrumsuz modellerin karşılaştırılması (Comparison of wall-framed without basement models)}

Çerçeveli perdeli model 9-11 için kat deplasmanları ve kat kesme kuvvetleri dağılımı Şekil 7'de, çerçeveli perdeli model 10-12 için kat deplasmanları ve kat kesme kuvvetleri dağılımı Şekil 8' de verilmiştir. 


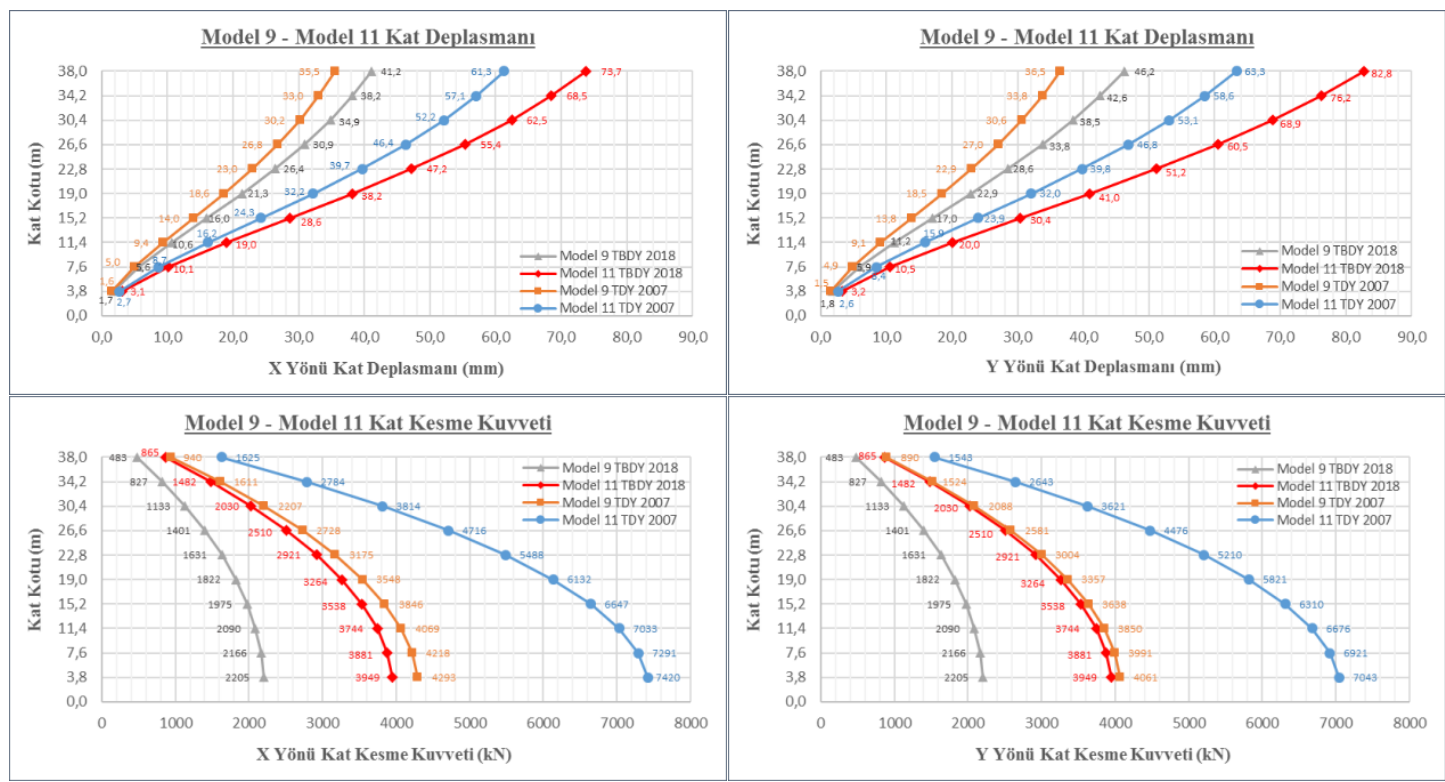

Şekil 7. Model 9-Model 11 X ve Y yönü kat deplasmanları ve kat kesme kuvvetlerinin TDY 2007 ve TBDY 2018' e göre karşılaştırması

Figure 7. Model 9-Model 11 X and Y direction floor displacements and floor shearing forces according to TDY 2007 and TBDY 2018

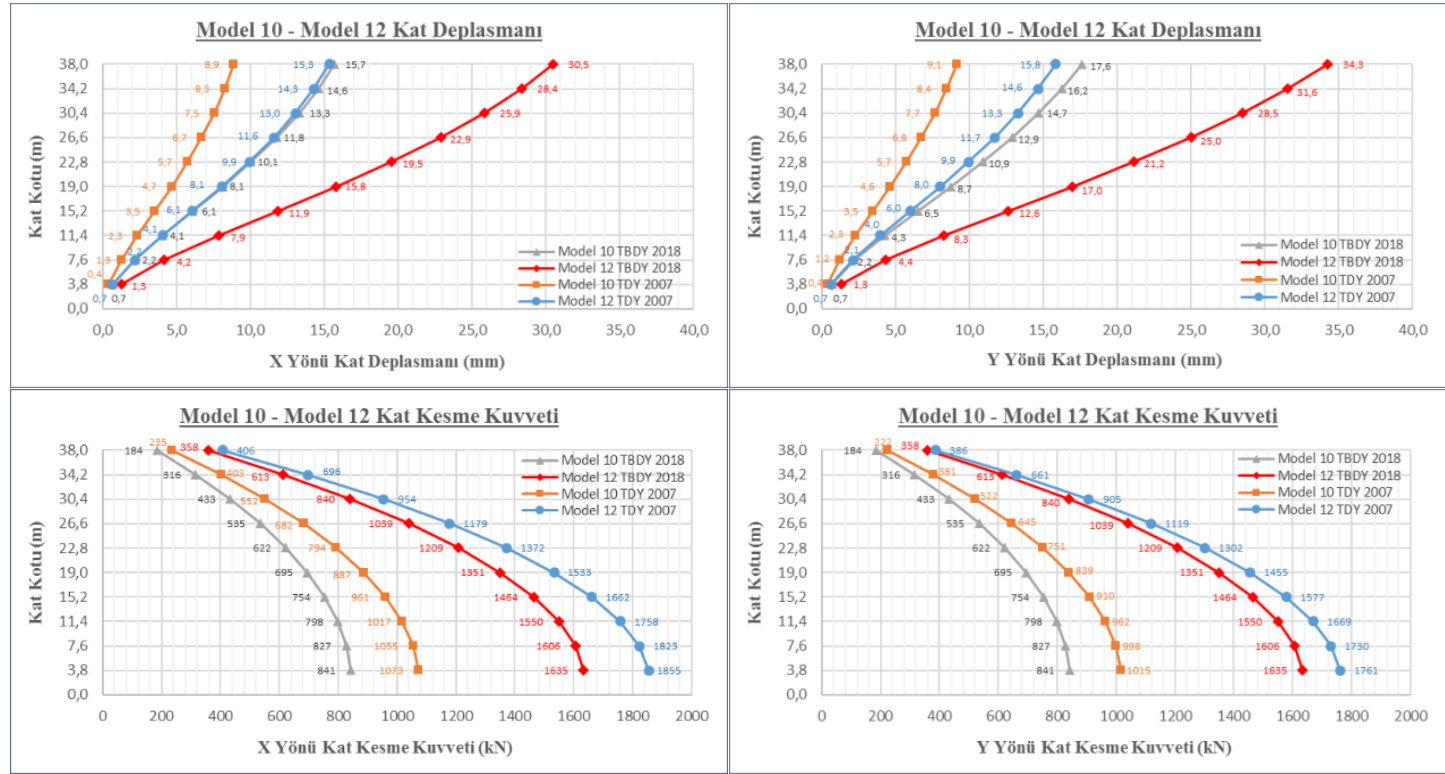

Şekil 8. Model 10-Model $12 \mathrm{X}$ ve $\mathrm{Y}$ yönü kat deplasmanları ve kat kesme kuvvetlerinin TDY 2007 ve TBDY 2018' e göre karşılaştırması

Figure 8. Model 10-Model 12 X and Y direction floor displacements and floor shearing forces according to TDY 2007 and TBDY 2018

\section{Çerçeveli - perdeli bodrumlu modellerin karşılaş̧tırılması (Comparison of wall-framed with basement models)}

Çerçeveli perdeli model 13-15 için kat deplasmanları ve kat kesme kuvvetleri dağılımı Şekil 9'da, çerçeveli perdeli model 14-16 için kat deplasmanları ve kat kesme kuvvetleri dağılımı Şekil 10’da verilmiştir. 

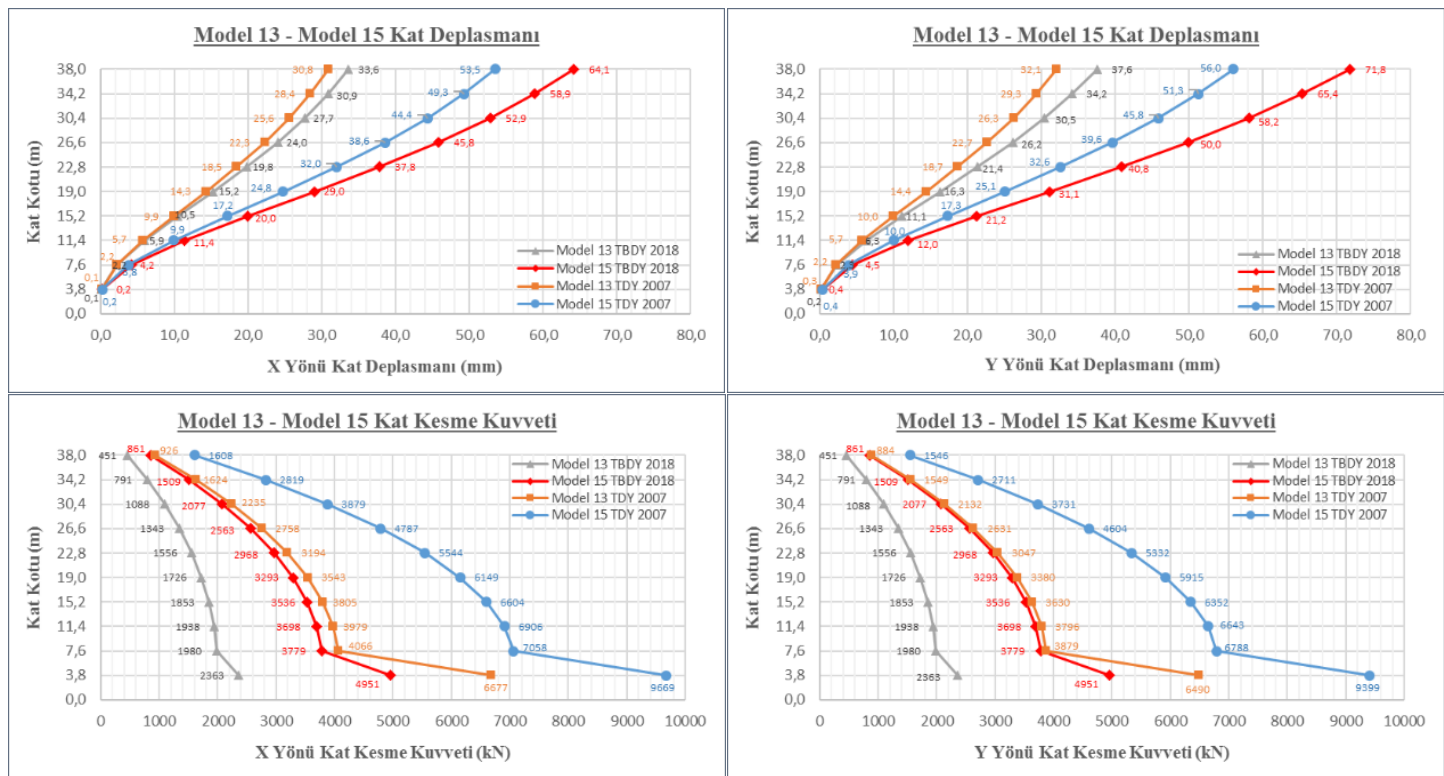

Şekil 9. Model 13-Model $15 \mathrm{X}$ ve $\mathrm{Y}$ yönü kat deplasmanları ve kat kesme kuvvetlerinin TDY 2007 ve TBDY 2018' e göre karşılaştırması

Figure 9. Model 13-Model $15 X$ and Y direction floor displacements and floor shearing forces according to TDY 2007 and TBDY 2018
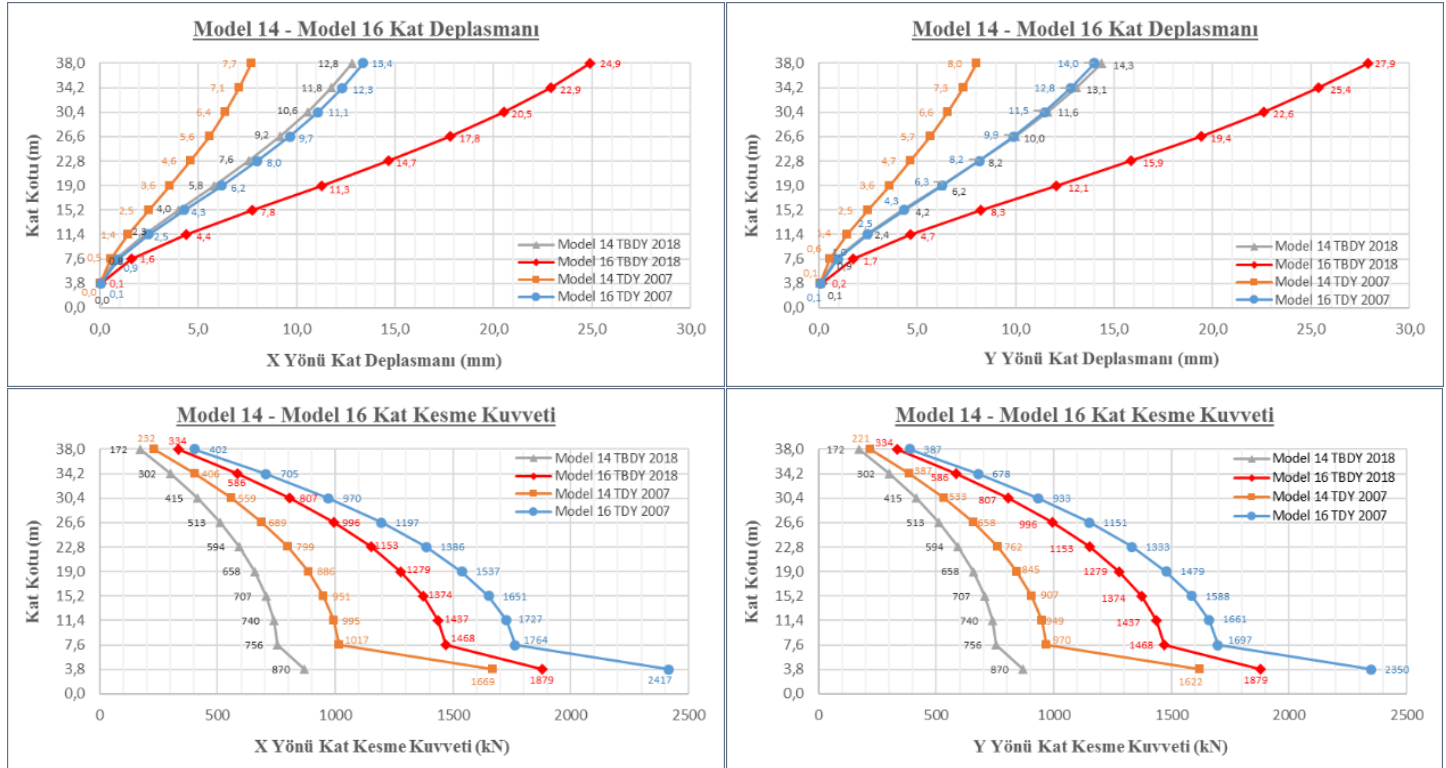

Şekil 10. Model 14-Model 16 X ve Y yönü kat deplasmanları ve kat kesme kuvvetlerinin TDY 2007 ve TBDY 2018' e göre karşılaştırması

Figure 10. Model 14-Model $16 X$ and Y direction floor displacements and floor shearing forces according to TDY 2007 and TBDY 2018

\section{SONUÇLAR ve ÖNERILLER (CONCLUSIONS and SUGGESTIONS)}

Yapılan analizlerden aşağıdaki sonuçlara ulaşılmıştır:

$\checkmark$ TBDY 2018' e göre yapılan analizlerde etkin kesit rijitlik katsayılarının kullanılmasının yapı periyodunu TDY 2007' ye göre arttırdığı görülmüştür. Yapı periyodundaki bu artışa bağlı olarak TBDY 2018' e göre yapılan analizlerde kat kesme kuvvetlerinde azalma olmuştur. Yapı periyodundaki bu artış çerçeveli-bodrumsuz modellerde $\% 43 \sim \% 46$, çerçeveli- bodrumlu modellerde $\% 43 \sim \% 47$, çerçeveli-perdeli bodrumsuz modellerde $\% 50 \sim \% 52$ ve çerçeveli-perdeli bodrumlu modellerde ise \%49 \%51 mertebelerindedir. 
$\checkmark \quad$ TBDY 2018' e göre yapılan analizlerde meydana gelen kat deplasmanının TDY 2007' ye göre artış gösterdiği görülmüştür. Buna göre kat deplasmanlarl;

- Çerçeveli-bodrumsuz modellerden İstanbul'da yer alanlarda \%31 \%42, Konya' da yer alanlarda ise $\% 100 \sim \% 188$,

- Çerçeveli-bodrumlu modellerden İstanbul' da yer alanlarda \%31 \%38, Konya' da yer alanlarda ise $\% 100 \sim 168$,

- Çerçeveli-perdeli bodrumsuz modellerden İstanbul' da yer alanlarda \%16 \%31, Konya'da yer alanlarda ise \%76 \%117,

- Çerçeveli-perdeli bodrumlu modellerden İstanbul' da yer alanlarda \%9 \%28, Konya' da yer alanlarda ise \%66 \%99 oranında artış göstermiştir.

Modellere ait kat deplasmanı oranlarına baktığımızda en fazla oranda deplasman artışının çerçevelibodrumsuz modellerde olduğu görülmektedir.

$\checkmark$ TBDY 2018' e göre elde edilen kat kesme kuvvetlerinde TDY 2007' ye göre elde edilen kat kesme kuvvetlerine göre genellikle azalma görülmüştür. Kat kesme kuvvetlerinde;

- İstanbul' da bulunan çerçeveli-bodrumsuz modellerde \%33 \%36 civarında bir azalma meydana gelirken Konya 'daki çerçeveli-bodrumsuz modellerden Z1-ZA zemin sınıfındaki modelde \%2 azalma meydana gelirken Z3-ZD zemin sınıfındaki modelde \%28 \%34 oranında bir artış olmuştur.

- Çerçeveli-bodrumlu olan İstanbul' daki modellerde kat kesme kuvvetinde \%50 \%62 oranında, Konya' daki modellerde ise $\% 7 \sim 43$ oranında bir azalma olmuştur.

- Çerçeveli-perdeli bodrumsuz olan İstanbul'daki modellerde kat kesme kuvvetinde \%44 \%49 oranında, Konya'daki modellerde ise \%7 \%22 oranında azalma olmuştur.

- Çerçeveli-perdeli bodrumlu olan İstanbul' daki modellerde kat kesme kuvvetinde \%47 \%65 oranında, Konya' daki modellerde ise \%20 \%48 oranında azalma olmuştur.

$\checkmark$ Her iki yönetmeliğe göre analizleri yapılan modellerde konum aynı kalırken zemin sınıfı TDY $2007^{\prime}$ ye göre $Z^{\prime}$ ' den Z3'e, TBDY 2018' e göre ZA' dan ZD' ye değiştiğinde modellerde meydana gelen kat deplasmanları ve kat kesme kuvvetleri TDY 2007' de de TBDY $2018^{\prime}$ de de artış göstermiştir.

- İstanbul'da bulunan çerçeveli-bodrumsuz modellerde konum aynı kalırken zemin sınıfı TDY 2007' ye göre $\mathrm{Z1}^{\prime}$ den $\mathrm{Z3} 3^{\prime}$ e değiştiğinde kat deplasmanında $\% 42 \sim \% 48$, kat kesme kuvvetinde $\% 42 \sim \% 4$, TBDY 2018'e göre ZA' dan ZD'ye değiştiğinde kat deplasmanında \%47, kat kesme kuvvetinde ise \%47 oranında bir artış olmuştur.

- Konya' da bulunan çerçeveli-bodrumsuz modellerde konum aynı kalırken zemin sınıfı TDY 2007' ye göre $Z 1$ 'den Z3' e değiştiğinde kat deplasmanında \%42 \%48, kat kesme kuvvetinde $\% 43 \sim \% 49$, TBDY 2018 ' e göre ZA' dan ZD' ye değiştiğinde kat deplasmanında \%95, kat kesme kuvvetinde ise \%95 oranında bir artış olmuştur.

- İstanbul'da bulunan çerçeveli-bodrumlu modellerde konum aynı kalırken zemin sınıfı TDY 2007' ye göre Z1' den Z3' e değiştiğinde kat deplasmanında \%53 \%60, kat kesme kuvvetinde \%27 \%31, TBDY 2018 'e göre ZA' dan ZD' ye değiştiğinde kat deplasmanında \%48, kat kesme kuvvetinde ise $\% 68$ oranında bir artış olmuştur.

- Konya' da bulunan çerçeveli-bodrumlu modellerde konum aynı kalırken zemin sınıfı TDY 2007' ye göre $Z 1^{\prime}$ den $Z 3^{\prime}$ e değiştiğinde kat deplasmanında \%51 \%60, kat kesme kuvvetinde \%28 \%32, TBDY 2018' e göre $Z^{\prime} A^{\prime}$ dan $Z^{\prime}$ ye değiştiğinde kat deplasmanında \%95, kat kesme kuvvetinde ise \%109 oranında bir artış olmuştur.

- İstanbul'da bulunan çerçeveli-perdeli bodrumsuz modellerde konum aynı kalırken zemin sınıfı TDY 2007' ye göre Z1' den Z3' e değiştiğinde kat deplasmanında \%73, kat kesme kuvvetinde \%73, TBDY 2018 'e göre $Z^{\prime} A^{\prime}$ dan $Z D^{\prime}$ ye değiştiğinde kat deplasmanında $\% 79$, kat kesme kuvvetinde ise $\% 79$ oranında bir artış olmuştur.

- Konya' da bulunan çerçeveli-perdeli bodrumsuz modellerde konum aynı kalırken zemin sınıfı TDY 2007' ye göre Z1'den Z3' e değiştiğinde kat deplasmanında \%72 \%74, kat kesme kuvvetinde \%73, TBDY 2018' e göre ZA' dan ZD' ye değiştiğinde kat deplasmanında \%95, kat kesme kuvvetinde ise \%94 oranında bir artış olmuştur. 
- İstanbul'da bulunan çerçeveli-perdeli bodrumlu modellerde konum aynı kalırken zemin sınıfı TDY 2007' ye göre Z1' den Z3' e değiştiğinde kat deplasmanında \%74, kat kesme kuvvetinde \%45, TBDY 2018 'e göre ZA' dan ZD' ye değiştiğinde kat deplasmanında \%91, kat kesme kuvvetinde ise \%109 oranında bir artış olmuştur.

- Konya' da bulunan çerçeveli-perdeli bodrumsuz modellerde konum aynı kalırken zemin sınıfı TDY 2007' ye göre Z1'den Z3' e değiştiğinde kat deplasmanında \%75, kat kesme kuvvetinde \%45, TBDY $2018^{\prime}$ e göre $Z^{\prime} A^{\prime}$ dan $Z^{\prime}$ ye değiştiğinde kat deplasmanında \%95, kat kesme kuvvetinde ise \%116 oranında bir artış olmuştur.

Yapılan çalışmada elde edilen sonuçlar neticesinde; TBDY 2018' de etkin kesit rijitlik katsayılarının kullanılması doğal titreşim periyotlarında ve kat deplasman miktarlarında artışa neden olmuştur. Bu artışa bağlı olarak yeni yönetmeliğe göre yapılan analizlerde kat kesme kuvvetlerinde genellikle azalma olduğu görülmüş̧ür.

TBDY 2018 ile birlikte zemin etkisi hesaplarda daha gerçekçi olarak etki etmektedir. Yerel zemin sınıfının sağlam zeminden daha kötü bir zemine doğru değişmesiyle kat deplasmanlarında ve kat kesme kuvvetlerinde görülen artış miktarının TDY 2007' ye kıyasla TBDY 2018' de daha fazla olduğu görülmüştür.

Yeni yönetmeliğin deprem tehlikesini daha gerçekçi olarak ortaya koyduğu düşünülmektedir. TBDY 2018' in uygulanması ile taşıyıcı sistem eleman boyutlarında artış beklenmektedir. Bina yükseklikleri farklı veya düzensizliklerin olduğu taşıyıcı sistem modelleri kullanılarak ya da ŞGDT yaklaşımına uygun modeller seçilerek yapılması önerilen benzer çalışmaların bu çalışmada elde edilen sonuçların değerlendirilmesi ve geliştirilmesi açısından yararı olacağı düşünülmektedir.

Bu çalışmadan elde edilen sonuçların İstanbul (Enlem 41.018071, Boylam 29.15173) ve Konya (Enlem 37.869972, Boylam 32.494208) için geçerli olduğu ve TDY 2007' ye göre birinci ve dördüncü derece deprem bölgesinde bulunan farklı koordinatlar için TBDY 2018 Deprem Tehlike Haritalarından farklı spektrum değerlerine ulaşılacağı için bu çalışmadaki sonuçları etkileyebileceği bilinmelidir.

\section{KAYNAKLAR (REFERENCES)}

AFAD, Türkiye Deprem Tehlike Haritası, https://tdth.afad.gov.tr ,ziyaret tarihi: 29.01.2021

DBYBHY, 2007, Deprem Bölgelerinde Yapılacak Binalar Hakkında Yönetmelik, Çevre ve Şehircilik Bakanlı̆̆ 1 , Ankara.

Demir, A., Kayhan A. H., “Deprem Yönetmeliği 2007 ve Türkiye Bina Deprem Yönetmeliği ile Uyumlu Zaman Tanım Alanında Analiz Sonuçlarının Karşılaştırılması", 4.Uluslararası Deprem Mühendisliği ve Sismoloji Konferansı, Anadolu Üniversitesi, Eskişehir, 11-13 Ekim 2017.

Erdem, M. M., Bikçe M., 2017, “Maksimum Azaltılmış Göreli Kat Ötelemelerinin Güncel (DBYBHY2007) ve Yeni Yönetmelik Taslağına (TBDY2016) Göre Mukayesesi", Çukurova Üniversitesi Mühendislik Mimarlık Fakültesi Dergisi, Cilt 32, No 2, 253-262.

Keskin, E., Bozdoğan K.B., 2018, “2007 ve 2018 Deprem Yönetmeliklerinin Kırklareli İli Özelinde Değerlendirilmesi", Kırklareli University journal Of Engineering And Sience, Cilt 4 No 1, 74-90.

Öztürk, M., 2018, “2018 Türkiye Bina Deprem Yönetmeliği ve Türkiye Deprem Tehlike Haritası İle ilgili İç Anadolu Bölgesi Bazında Bir Değerlendirme", Selçuk Teknik Dergisi, Cilt 17, No 2, 31-42.

Öztürk, H., Demir A., Dok G., Güç H., “Betonarme Kolonların Etkin Kesit Rijitlikleri Üzerine Yönetmeliklerin Yaklaşımları", 4.Uluslararası Deprem Mühendisliği ve Sismoloji Konferansı, Anadolu Üniversitesi, Eskişehir, 11-13 Ekim 2017.

Sümeli, O. H., 2017, Mevcut Betonarme Bir Bina Üzerinde 2007 ve 2017 Deprem Yönetmeliklerinin Karşılaştırılması, Yüksek Lisans Tezi, İstanbul Teknik Üniversitesi, Fen Bilimleri Enstitüsü, İstanbul.

TBDY, 2018, Türkiye Bina Deprem Yönetmeliği, Çevre ve Şehircilik Bakanlığı, Ankara.

Tunç, G., Tanfener T., “2007 ve 2016 Bina Deprem Yönetmeliklerinin Örneklerle Mukayesesi”, 3.Ulusal Yapı Konferansı ve Sergisi Teknik Tasarım, Güvenlik ve Erişilebilirlik,TMMOB Mimarlar Odası, Ankara, 24-26 Kasım 2016. 
Zorlu, M., Akbaş B., 2017, "Yeni Türkiye Bina Deprem Yönetmeliği’ne Göre Çelik Yapı Tasarımı”, Uluslararası Katılımlı 7.Çelik Yapı Sempozyumu, Gaziantep, 292-305, 2017. 